\title{
A gestão escolar inclusiva, cosmopolita e multicultural
}

\author{
Marisa Batista ${ }^{a}$ \\ a Doutoranda no CEIED, Instituto de Educação, Universidade Lusófona de Humanidades e \\ Tecnologias, Lisboa, Portugal, marisa.investigadora@yahoo.com
}

\section{Resumo}

A presente comunicação é fruto da tese em construção intitulada $O$ cidadão do mundo e a organização ética da escola que analisa as relações sociais estabelecidas nas instituições educativas como responsáveis pela sustentabilidade e manutenção das culturas organizacionais. Objetiva-se demonstrar que o gestor escolar pode liderar um currículo inclusivo, cosmopolita e multicultural com dinamismo e democracia apoiando práticas docentes autónomas que combatam a discriminação e incluam os stakeholders no processo de elevação educativa e de coesão social. A mobilidade demográfica é uma realidade no planeta e a escola está plural. Um dos instrumentos de pesquisa utilizados na investigação de doutoramento é o Projeto Jovem Em Cena da Escola Estadual Professor António José Leite, localizada na Cidade de São Paulo-Brasil que difunde uma prática inclusiva e inovadora. O projeto de teatro apresenta musicais com releituras de obras cénicas mundiais e obras originais. Os participantes com as professoras criam o argumento, roteiro, cenário e figurino. Os stakeholders que são: pais, alunos, patrocinadores, artistas e a comunidade em geral trabalham juntos num processo coletivo de responsabilidade social.

Palavras-chave: Multiculturalismo, coesão social, qualidade de ensino, cosmopolita, responsabilidade social.

\section{Introducão}

Esta comunicação é parte integrante da tese de doutoramento que corre a termos $O$ cidadão do mundo e a organização ética da escola que na educação comparada entre Brasil e Portugal analisa o fluxo migratório presente no globo como difusor de escolas multifacetadas e multiculturais, mas que enfrentam sérios problemas relacionais em sua 
cultura organizacional com a discriminação a essas populações e às diferentes identidades nelas presentes.

Existem pesquisas significativas em Portugal e no Brasil que denunciam nas diferentes identidades presentes nas escolas violações causadas por discriminações, xenofobias e preconceitos. Não compreendidas, repelidas e esquecidas essas populações desenvolvem o sentimento de inferioridade e exclusão, por consequência, a nacionalidade, a etnia, a religião, a opção sexual e o género corroboram como fatores interferenciais negativos ao insucesso académico desses alunos. A base de interpelação deste paper traz a school leadership como impulsionadora de um contexto educativo intercultural. $\mathrm{Na}$ investigação identifica-se a gestão, a liderança escolar e o corpo docente preocupados com a emancipação humana e com a garantia da autonomia dos professores. As ações dos diretores de escola desses objetos (Brasil e Portugal) e de seus professores defendem a coesão social, a justiça, a inclusão, o cosmopolitismo de resistência e o multiculturalismo interativo (Benavente, 2004; Estêvão, 2011; Souza Santos, 2007; Luck, 2010; Lima, 2011 e Candau, 2008).

As populações educativas discriminadas nas diferentes pesquisas existentes são vítimas das desigualdades socioeconómicas, autoestima e inserção social. São diferentes constructos identificados pela Academia que contribuem à vulnerabilidade dessas pessoas carentes de proteção social: a falta de oportunidade de empregos, baixo rendimento per capita, ausência de moradia e alimentação condignas (Ennes, 2018).

Por outro lado, os gestores escolares e os docentes enquanto responsáveis pelo avanço pedagógico-social desses alunos não podem esquecê-los ou deixá-los no anonimato. A escolarização de qualidade e o equilíbrio sustentável nas relações interpessoais dos stakeholders processam uma cultura democrática, equitativa e interativa que necessita de equipamentos adequados, famílias presentes, ações autónomas de professores e dos demais profissionais difundindo um espaço acessível e de pertencimento a todos/das (Formosinho et al., 2016, p. 49) .

Portanto, a escola para todos não é homogénea atende pessoas de várias realidades, migrantes ou não, com fenótipos e genótipos diferenciados pertencentes às várias camadas sociais. Na metodologia bibliográfica exploratória da investigação a Academia identifica num contexto geral das escolas a ausência de um gate pelo diretor escolar para que todos adentrem e estejam presentes no processo educativo.

Dessa forma a construção coletiva da cultura organizacional escolar adir-se-á aos traços, às histórias e aos atos dos stakeholders na garantia do acesso e permanência de todos/das assegurados na dignidade humana e em seus múltiplos significados (Canário, 2005). 
Neste paper objetiva-se demonstrar o apoio administrativo escolar incondicional na autonomia docente concedido pela equipa gestora de uma escola pública brasileira na criação de um dispositivo pedagógico diferenciado. A professora Denise Biella com o Projeto Jovem Em Cena, instrumento empírico - atraem dezenas de jovens/ano como participantes e integrantes que conscientizam uma região em São Paulo, Brasil à tolerância, ao respeito e à ética na realidade cosmopolita e intercultural do mundo.

\section{A elevação da qualidade educativa, a necessidade do currículo multicultural e o diretor de escola}

A escola, organização social eficaz e prestadora de serviços, tem em sua ação a responsabilidade de atempar objetivos, recursos, pedagogias, tecnologias em sua estrutura formal e informal à busca da elevação da qualidade de ensino. No fortalecimento do compromisso à comunidade garante-se a inserção de agentes transformadores da sociedade civil enquanto cidadãos do mundo dotados de competências e capacidades de aprendizagens dum saber que foi sistematizado e historicamente acumulado (Lima, 2011; Rios, 2011; Formosinho et al. 2016). É vital nessa escola cidadã constituir valores que viabilizem o respeito e a paz.

Contudo, as escolas devem garantir o desenvolvimento intelectual, procedimental e comportamental estabelecidos à emancipação e elevação das pessoas. As especificidades organizacionais e seus contextos, como salientam Estêvão[1998], Formosinho e Machado [2008], Lima[2011] e Batista[2017], sugerem mudanças na atuação dos sistemas políticos homogéneos: o controlo administrativo exagerado, a burocracia excessiva e punitiva, a visão unilateralista do sistema educativo, a autonomia organizacional falseada, a direção dos agrupamentos sobrecarregadas, os objetivos verticalmente estabelecidos, homogeneização dos currículos e a ausência de diálogos entre as organizações do sistema educativo (Batista, 2019, p. 115).

É na perspetiva social, histórica e ética da escola com suas interações sociais através dos símbolos, objetos, pessoas e acontecimentos externos (Bronfenbrenner 1977, 1996, 2011) que o desenvolvimento dos alunos e dos profissionais se constroem. As relações sociais estabelecidas na organização escolar possibilitam o multiculturalismo interativo (Candau, 2008) à construção dum ambiente saudável fortalecidos no respeito mútuo e na solidariedade. Desta forma, os stakeholders combatem toda forma de preconceitos, discriminações e xenofobias que destroem a manutenção e a globalidade da vida (Batista, 2019).

Recentes pesquisas em Portugal comprovam a existência de discriminações e preconceitos aos afrodescendentes e às populações provenientes dos Países Africanos de Língua Oficial Portuguesa. A investigação de Monteiro et al. (2009) identificam-se preconceito étnico- 
racial entre crianças brancas e seus pares em idade infantil de 6 a 10 anos. Outros estudos denunciam a dificuldade das populações africanas e dos afrodescendentes acederem ao Ensino Superior, diferente da realidade dos jovens autóctones da mesma idade (Roldão, 2015; Seabra et al., 2016). As investigadoras Araújo e Maeso (2010) pesquisaram os manuais escolares de história e concluíram que os africanos são representados de forma inferiorizada e as lutas de libertação nacional em África são abordadas de forma despolitizada e sem importância.

No Brasil, investigação realizada pela Fundação do Instituto de Pesquisas Económicas a pedido do Instituto Nacional de Estudos e Pesquisas Educacionais Anísio Teixeira para avaliar o grau de preconceito e discriminação no ambiente escolar trouxe uma revelação dura e assustadora. Essa pesquisa coordenada por Afonso Mazzon (2009) da Universidade de São Paulo concluiu que 96,5\% dos entrevistados têm preconceito com relação a portadores de necessidades especiais, 94,2\% têm preconceito étnico-racial, 93,5\% de género, $91 \%$ de geração, $87,5 \%$ socioeconómico, $87,3 \%$ com relação orientação sexual e $75,95 \%$ têm preconceito territorial. Descreve a pesquisa que as escolas são ambientes fomentadores de discriminação inexistindo alguém que não tenha identificação de três a cinco áreas de preconceito. Culturalmente o país é miscigenado e os dados do Instituto Brasileiro de Geografia e Estatística (2011) identificou que 84 milhões de brasileiros se autodeclararam pardos.

As Organizações das Nações Unidas decretaram a implementação da Década Internacional dos Afrodescendentes (2015-2024) de forma a conscientizar e expandir a tolerância, mas "em todo o mundo a população afrodescendente continua a ser alvo de discriminação a vários níveis, da habitação às escolas, do trabalho à representação política ou à justiça" (Zeid Ra'ad Al Hussein, 2017).

O rumo da instituição educativa é condicionado pelo diretor de escola que quando desempenha o seu papel através do projeto político educativo com eficiência, força, consistência e coerência à ação educadora emerge numa intrincada tarefa de harmonizar a estrutura complexa e moderna do espaço educativo. A investigadora dissemina a importância da liderança educativa nas escolas do século XXI como função nuclear no desenvolvimento da qualidade de ensino, da liderança do currículo interativo e na sustentabilidade da cultura organizacional que enfrenta burocracias cruéis, disputas de poder, arena política e o fracasso do sistema social (Lima, 2011, p. 155). 


\section{A mobilidade demográfica e a coesão social}

A mobilidade populacional trouxe uma nova onda demográfica aos países e uma crise migratória sem precedentes ao globo com contingências humanas não esperadas e não planeadas. Aos seres humanos que buscam a mudança restam a indiferença e o não acolhimento. Segundo as Organizações das Nações Unidas (2017) estima-se que 258 milhões de pessoas vivam num país diferente do país em que nasceu.

Não é possível banalizar-se com mortes causadas pelos naufrágios no Mediterrâneo nem tão pouco ficar indiferente com a miséria que aflige a Venezuela e outros países em desenvolvimento. Contudo, nas escolas as comunicações e interações entre os atores sociais com diferentes identidades atropelam-se e conflituam-se. Alunos migrantes ou possuidores de variadas situações socioeconómicas, de etnias, de género, orientação sexual e de limitações de toda espécie não são aceites. Nascem territórios separados dentro da mesma unidade educativa que são os guetos impedindo a interculturalidade. Urge despertar a autoconsciência, a responsabilidade social, a sensibilidade, a tolerância e a mudança de mentalidades (Morin, 2001).

O corte transversal do currículo oculto e inclusivo deve ser liderado pelo diretor de escola ancorado na ética e no direito dos alunos de estarem, acederem e permanecerem àquele espaço (Batista, 2017). A democratização escolar é consciência ativa fonte geradora de projetos autónomos dos professores e alunos com a partilha de responsabilidades (Batista, 2018). A liderança educacional compete: motivar, autonomizar, confiar, unir, conectar, interagir e harmonizar a cultura organizacional com os colaboradores, alunos, personagens da comunidade e famílias fomentando a coesão e a justiça social.

Segundo Lück (2012, p. 35) a arte de liderar resume-se em: “(i) Motivar[todos]para uma atividade; (ii) Ter propósitos claros de orientação; (iii) Garantir processos sociais dinâmicos, interativos e participativos; (iv) Inserir na organização escolar valores educacionais elevados; (v) Possuir orientação para o desenvolvimento e aprendizagem de forma contínua.”

O líder é o espelho e suas atitudes coadunam com o desenvolvimento da visão e missão da instituição. Existem vários tipos de liderança e as escolas são avaliadas (OCDE, 2014) na complexidade: de elevação da cultura e do clima organizacional, aplicação de recursos, mobilização das famílias/comunidade e do grau de organização e disciplina. Constata-se a elevação local com o desenvolvimento intelectual da escola segundo pesquisas recentes, relacionados com o respeito na formação de um ethos próprio de valores, atitudes e comportamentos institucionais (Torres \& Palhares, 2009, pp. 81-83). 


\section{O instrumento empírico Projeto Jovem Em Cena}

Um dos instrumentos empíricos da tese de doutoramento em curso $O$ cidadão do mundo e a organização ética da escola é o Projeto Jovem Em Cena. É um dispositivo didáticosociocultural inovador que acontece na Escola Estadual Professor António José Leite no Brasil - Cidade de São Paulo. Configura-se em um teatro voluntário criado e liderado pela professora de Língua Portuguesa Denise Biella auxiliada pela sua filha professora Juliana Biella. Retrata-se nas obras cénicas versões originais e releituras de textos teatrais emancipatórios com diferentes abordagens: dos negros africanos, da mulher, dos portadores de deficiências, dos direitos humanos, clássicos literários e musicais dentre outros. Os alunos, pais, comunidade, empresários e patrocinadores todos voluntários participam na construção dos figurinos, roteiro, da cenografia, filmagem, marketing e apoiam todo o projeto. Hoje seus ensaios acontecem aos sábados.

A professora Denise Biella determinada em trabalhar a interdisciplinaridade entre Língua Portuguesa e Artes combatendo a discriminação revolucionou a escola, a Zona Norte da Cidade e a Rede de Ensino Estadual trazendo inovação pedagógica e cultura a uma região vulnerável do Brasil. O projeto teve início no ano de 2008 e permanece até os dias atuais.

\section{Análise dos resultados}

Apura-se que o projeto teve início no ano de 2008 com turmas da Educação de Jovens e Adultos que encenaram a releitura de Tristão e Isolda. Em 2009 o projeto atingiu o Ensino Médio e encena o clássico Romeu e Julieta de William Shakespeare. Em 2011 nasceu a Trilogia Ritmo e Cultura e a professora relata que com a inspiração de um trabalho anterior surge o próximo.

Na peça de teatro Ritmo e Cultura 1 a idealizadora do projeto inseriu alunas portadoras de necessidades especiais de mobilidade (cadeirantes de rodas) que nas inscrições democráticas optaram por fazer parte do Projeto. Os espetáculos são apresentados em junho e novembro com reflexões socias e de autoconhecimento. O senso crítico das coisas da vida e do mundo sensibilizam a comunidade.

Novembro de 2011, nasceu a obra Tudo tem o seu tempo. O aluno Weslley Nicolas quis mostrar à escola um trabalho que assistiu na Internet e a ideia saiu muito bem à professora. Surgiu a obra Tudo - com dança e dramatização sem falas. O título originou-se no decorrer dos ensaios em que a palavra tudo foi identificada como importante em situações experienciadas pelo grupo. Com a ideia do aluno o desafio da obra foi criar um figurino à abstração e personificação dos elementos água, terra, fogo e ar que compõem o mundo: 
A criação de tudo que existe, tudo ao que o ser humano e tudo o que lhe acontece como consequência de suas escolhas(...). O Criador molda e dá vida à criatura que vai conhecer o que é bom e o que não é. Pensámos em mostrar além da criação do ser humano, a criação dos quatro elementos água, terra, fogo e ar.(...)Neste ponto faltava ainda algum quadro no qual as alunas com deficiência física pudessem participar da dança. Mais uma vez elas encerrariam o espetáculo: elas seriam os anjos da apresentação (Revista Jovem Em Cena 10 anos, 2018, p. 6).

À direção escolar entende que apoiar não é somente aderir a ideia. Peremptoriamente no ato educativo é acreditar, motivar, planear, incentivar, confiar e autonomizar a escola proporcionando meios e insumos para que projetos se realizem. Foi o que fez e faz a gestão educativa ao Projeto Jovem Em Cena. Relata a professora Denise Biella há treze anos na escola o apoio incondicional da gestão escolar:

O que foi mais importante para mim e até hoje ainda que ajudou a fazer de mim a profissional que eu sou hoje foi a confiança e a liberdade. A confiança que a gestão o grupo gestor da escola teve em que eu fizesse o meu melhor e a confiança para que eu utilizasse todos os espaços da escola. Esta confiança e essa liberdade permitiram com que eu pudesse acompanhar os alunos em séries consecutivas.(...)Isto foi muito importante por dois motivos, foi possível dar conta, dar seguimento àquilo que ficou em aberto e acompanhar efetivamente o desenvolvimento do aluno, sem contar que o facto de estar com eles há mais tempo fez com que se estreitasse os laços, a relação professor-aluno com maior confiança entre as partes(...) diminuindo sensivelmente a indisciplina. A confiança e a liberdade na abertura incondicional da escola para que eu trabalhasse a Arte(...). Hoje colocamos no palco a releitura de um clássico O Fantasma da Ópera. Isto só foi possível porque tudo o que estava ao alcance da gestão foi feito (Denise Biella, setembro/ 2016).

A escola conta com uma realidade perversa, os alunos são constantemente perseguidos por traficantes de estupefacientes além de muitos possuírem problemas ligados à desigualdade socioeconómica da periferia violenta da Vila Nova Cachoeirinha. Mas, com as informações

e o conhecimento disseminados pelo Projeto Jovem Em Cena expande-se a multiculturalidade e o cosmopolitismo na Comunidade Educativa com a mensagem de amor, respeito e reconhecimento à pluralidade cultural. As peças de teatro são compostas com: música, dança, figurino, imagens, efeitos digitais e sonoros com a abrangência histórico-cultural de vários países: Brasil, Japão, Índia, Marrocos, Nigéria, França, Áustria, Espanha, Inglaterra, Portugal, Estados Unidos na real interdisciplinaridade da Arte com o roteiro e o argumento da Língua Portuguesa.

\section{Metodologia}

Ao instrumento de investigação utiliza-se o método qualitativo da pesquisa bibliográfica na construção de uma hermenêutica explicativa dos fenómenos revelados. Salienta-se 
interpretar a dialética entre os atores sociais e o meio na abordagem inicial compreendendose a significação do instrumento de pesquisa àquela realidade apreendida (Prodanov \& Freitas, 2013). Realizaram-se várias observações no decorrer do projeto identificando o impacto transformacional na vida de seus participantes e na Região.

Para não interpretar equivocadamente o significado original, os intérpretes devem empregar algum tipo de método que lhes possibilite um afastamento de seus referenciais históricos. Quando corretamente empregado, o método é um meio que permite aos intérpretes alegar uma atitude puramente teórica de observador (Schwandt, 2006, p. 197).

Os dados do Projeto Jovem Em Cena foram recolhidos do público alvo integrantes do ano de 2008 até 2019. Aplicou-se entrevistas semiestruturadas do mês de setembro de 2016 a agosto de 2019, compondo-se em 30 relatos de integrantes, pais, patrocinadores, artistas e professores a respeito do Projeto, 03 narrativas de Ex-membros e 05 depoimentos de Exalunos. Dentre as perguntas mais significativas aos integrantes estão: Qual a importância do Projeto em sua vida? O que mudou no seu percurso académico ao ingressar no Projeto Jovem Em Cena?

Quando eu entrei no projeto que a escola apoiava Jovem em Cena, projeto de alunos voluntários e eu era uma pessoa muito retraída para eu falar em público era muito difícil muito tímida (...) aprendi o trabalho em equipa aprendi a batalhar por um sonho (...) Eu sinto até falta do jeito que a diretora chamava a gente de leiteanos e leiteanas (...) quem faz a escola é o aluno mas se essa escola não tiver administração não tem como o aluno fazer a escola, porque para o aluno fazer escola tem que ter alguém que oiça, que nos oiçam, tem que ter alguém que creia na gente e a diretora acreditava. Acreditava que poderíamos fazer uma escola melhor e acreditava que poderíamos crescer sim! E acredito que muitos que estudaram ali e estudam pensam da mesmo forma que eu e vão crescer na vida pelo que a diretora representou... (Marina Rodrigues, outubro 2017).

Os depoimentos foram confrontados com os documentos oficiais da escola que é objeto de investigação e por diversos registos culturais que são públicos em vídeos disponibilizados na Internet via ferramenta do YouTube. Constantemente a investigadora mantém-se atualizada a respeito das inovações do Projeto e de seus integrantes interagindo com a idealizadora do Projeto em plataforma on-line.

\section{Considerações finais}

Os alunos ligados ao projeto possuem um alto desenvolvimento de suas capacidades e competências cognitivas e académicas. Muitos que foram integrantes possuem inserção em Universidades Públicas com cargos importantes em distintas empresas com destacada 
relevância social. Interagem uns com os outros, independente da religião, etnia, género, orientação sexual ou de serem portadores de necessidades especiais. Forma-se um emaranhado de histórias ricas e narrativas multiculturais que se complementam entre si originando um enredo coletivo e um puzzle de significados e sentidos (Goodson, 2007) na vida desses jovens e crianças. Nasce um orgulho natural e a elevação da autoestima dos integrantes do projeto e dos alunos daquela escola pelo reconhecimento local da importância do trabalho ali desenvolvido.

Há um misto na composição da comunidade educativa por miscigenados europeus, indígenas, africanos, árabes e asiáticos que convivem com respeito no mesmo espaço numa demonstração viva da interculturalidade (André, 2012). São onze anos do Projeto Jovem Em Cena adicionando a cultura cosmopolita e multicultural em uma região, potencializando a Arte que inspira as pessoas e transforma vidas. A infraestrutura do Projeto conta com um anfiteatro arrojado e equipado com novas tecnologias: projetor de vídeo profissional, iluminação, mesa de som, colunas com amplificadores, microfones sem fio, cortinas eletrónicas, máquinas fotográficas, computadores, instrumentos musicais e filmadoras. Esses equipamentos são confiados pela equipa gestora à professora idealizadora do Projeto. As gravações do making of, das apresentações e entrevistas do Projeto são realizadas por Andressa Tarquini que se tornou voluntária, sensibilizada pela iniciativa de responsabilidade social fazendo um investimento pessoal em outros equipamentos profissionais de imagem. Os demais professores da escola apoiam e contemplam o projeto.

Entende-se que as professoras são missionárias e militantes - pérolas da educação brasileira - comprometidas com a elevação humana, académica, criativa e ética dos alunos apesar de receberem baixíssimos salários. A crise brasileira só fez aumentar as desigualdades e os alunos quando possuem um Projeto como o Jovem Em Cena transferem sentimentos e extravasam emoções. A atriz global laureada, cantora, compositora e versionista brasileira Alessandra Maestrini visita o projeto, faz uma palestra, realiza jogos dramáticos com os participantes do Projeto e relata:

O que vocês têm aqui é muito especial é importante que vocês saibam disto, uma energia, um talento, uma coesão, uma amorosidade que é muito importante e que faz muita diferença no resultado criativo porque quando a gente sai do amor, a gente sai da criatividade, entra no ego e não entra na relação isto é até difícil(...). A base da criação está na base da probabilidade das relações, então quando você fecha uma porta é menos um na criatividade.(...)É muito lindo o que vocês têm aqui, é muito espetacular!(..)Que vocês continuem porque eu sei que vão fazer um excelente trabalho, um lindo tudo, parabéns muitos parabéns a todos vocês!(Alessandra Maestrini, agosto/2016).

Conclui-se com a hermenêutica qualitativa do instrumento empírico que a realização desse projeto cultural-socioeducativo corrobora para uma consideração nova dos alunos, favorece as interações coletivas entre os stakeholders que trouxeram evidentes avanços nas 
aprendizagens dos jovens. Identifica-se que as crianças e jovens quando conhecem outras culturas ampliam o próprio repertório de vida, reconhecem nas culturas diferentes outras histórias e possibilidades, melhoram as capacidades linguísticas e seus léxicos, aumentam as competências literárias e a criatividade validando o proactivismo juvenil.

Levar as famílias à escola é um outro feito louvável deste projeto que evidencia a conexão entre escola/comunidade numa objetiva possibilidade de democratização do espaço escolar com movimento e participação tão necessários às escolas neste novo milénio.

A metodologia da professora Denise Biella em ir além com seus alunos que são despertados na interdisciplinaridade das Artes/Língua Portuguesa transforma-os em cidadãos do mundo, agentes da sociedade civil dotados de tolerância, respeito, amor e reconhecimento da pluralidade cultural. Estimula-se com a prática docente o desejo dos alunos em aprender, em estar e em conviver.

\section{Agradecimentos}

Infelizmente, vítima de xenofobia e violência urbana tragicamente uma das integrantes do Projeto que sempre combateu todas as formas de discriminação foi assassinada brutalmente, a transexual Gabriel Borges, com o nome artístico de Gabi Blak em dezembro de 2018. A ela, às professoras Denise Biella, Juliana Biella e ao Grupo do Projeto Jovem Em Cena agradeço pela essência deste trabalho.

\section{Referências}

André, J. M. (2012). Multiculturalidade, identidades e mestiçagem: o diálogo intercultural nas ideias, na política, nas artes e na religião. Coimbra: Palimage

Araújo, M.; Maeso, S. R. (2010). O Eurocentrismo nos Manuais Escolares de História Portugueses, Estudos de Sociologia(UNESP), 15 (28), 239-270.

Batista, M.(2017). A gestão no espaço escolar: Como atingir uma pedagogia de excelência? Saarbrücken-Alemanha: Novas Edições Académicas(ISBN: 978-3-330-20446-1).

Batista, M.(2018). A educação multicultural e cosmopolita, In Lopes, R. P., Pires, M. V., Castanheira, M. L. P., Silva, E. M., Santos, G., Mesquita, C., \& Vaz, P. M. F. (2018). III Encontro Internacional de Formação na Docência (INCTE): livro de atas, 70-77. Bragança, Portugal: Instituto Politécnico de Bragança (ISBN: 978-972-745-241-5).

Batista, M.(2019). O gestor escolar e a coesão social na escola, In Mesquita, C., Lopes, R. P., Silva, E. M., Santos, G., Patrício, R., \& Castanheira, L. (2019). IV Encontro Internacional de Formação na Docência (INCTE): livro de atas, 113-124. Bragança, Portugal: Instituto Politécnico de Bragança (ISBN: 978-972-745-259-0). 
Benavente, A. (2004). O pacto educativo para o futuro: um instrumento estratégico para o desenvolvimento educativo em Portugal. Revista Iberoamericana de educación, 34(1), 69-108.

Biella, D.: depoimento[setembro/2016]. Entrevista concedida a Marisa Batista. São Paulo - Brasil. Disponível em: https://www.youtube.com/watch?v=y-qIc-ONPpc

Brasil, O. N. U. (2017). Organização das Nações Unidas. Objetivos de Desenvolvimento Sustentável. Disponível em: http://www. itamaraty.gov.br

Bronfenbrenner, U. (1979). The ecology of human development. Harvard university press.

Bronfenbrenner, U. (1996). A ecologia do desenvolvimento humano (Vol. 80). Porto Alegre: Artes Médicas.

Bronfenbrenner, U. (2011). Bioecologia do desenvolvimento humano: tornando os seres humanos mais humanos. Porto Alegre: Artmed Editora.

Canário, R. (2005). O que é a escola? Um "olhar" sociológico. Porto: Porto editora.

Candau, V. M. (2008). Multiculturalismo e educação: desafios para a prática pedagógica. Multiculturalismo: diferenças culturais e práticas pedagógicas. Petrópolis: Vozes, 13-37.

de Almeida, R. R. (2004). Sociedade bit: Da sociedade da informação à sociedade do conhecimento. Lisboa: Quid Juris.

Ennes, M.; Ramos, N.; Suaréz, B. O lugar do interculturalismo nas políticas imigratórias em Portugal e Espanha. Revista TOMO, n. 32, 2018.

Estêvão, C. V. (2011). Democracia, Direitos Humanos e Educação: para uma perspectiva crítica de educação para os direitos humanos. Revista Lusófona de Educação, (17), 11-30.

Formosinho, J., Alves, J., \& Verdasca, J. (2016). Nova Organização Pedagógica da Escola: caminhos de possibilidades. Gaia, Portugal: Fundação Manuel Leão.

Goodson, I. (2007). Currículo, narrativa e o futuro social. Revista Brasileira de Educação, 12(35), 241-252. Disponível em: http://www.scielo.br/pdf/rbedu/v12n35/a05v1235

Hussein, Z. R. A. Comissário para os Direitos Humanos das Nações Unidas, entrevista concedida ao Jornal O Público em novembro/2017. Disponível: https://www.publico.pt/2017/11/25/sociedade/noticia/decada-dos-afrodescendentes-da-onucontinua-invisivel-em-portugal-1793910

IBGE (Instituto Brasileiro de Geografia e Estatística) (2011), Características Étnico-Raciais da População: Um Estudo das Categorias de Classificação de Cor ou Raça, 2008.Instituto Brasileiro de Geografia e Estatística, Ministério do Planejamento, Orçamento e Gestão. Rio de Janeiro, IBGE.

Libâneo, J. C. O sistema de organização e gestão da escola In: Libâneo, J. C. Organização e Gestão da Escola - teoria e prática. $4^{\mathrm{a}}$ ed. Goiania: Alternativa, 2001.

Lima, L. C. (2011). Apresentação [a]" Administração escolar: estudos" ( $N^{\circ} .1^{a}$ Edição). Porto: Porto editora. 
Lück, H. (2010). Conceções e processos democráticos de gestão educacional. Petrópolis: Editora Vozes Limitada.

Lück, H. (2012). Liderança em gestão escolar. Petrópolis: Editora Vozes Limitada.

Lück, H. (2017). Gestão educacional: uma questão paradigmática. Petrópolis: Editora Vozes Limitada.

Rodrigues, M. (outubro, 2017). Entrevista concedida a Marisa Batista. São Paulo, Brasil.

Disponível em https://www.youtube.com/watch?v=y-qIc-ONPpc

Maestrini, A. (agosto, 2016). Entrevista concedida ao Projeto Jovem Em Cena. São Paulo, Brasil.

Disponível em https://www.youtube.com/watch?v=5jr6CBiCm2M\&t=39s

Morin, E.(2001). La mente bien ordenada: repensar la reforma, reformar el pensamiento. Barcelona: Seix Barral.

Monteiro, M. B., Dalila F. e Rodrigues R. (2009). The development of intergroup bias in childhood: how social norms can shape children's racial behaviors, International Journal of Psychology, 44 (1), 29-39.

OCDE, O. (2014). TALIS 2013 results: An international perspective on teaching and learning. OECD Publishing.

Prodanov, C. C., \& de Freitas, E. C. (2013). Metodologia do trabalho científico: métodos e técnicas da pesquisa e do trabalho acadêmico- $2^{a}$ Edição. Nova Hamburgo: Editora Feevale.

Rios, T. A. (2011). Ética e competência. Ed. São Paulo, Cor.

Roldão, C. (2015).Fatores e Perfis de Sucesso Escolar "Inesperado": Trajetos de Contratendência de Jovens das Classes Populares e de Origem Africana. Tese de Doutoramento. Lisboa: Instituto Universitário de Lisboa.

Santos, B. D. S. (2007). Para além do pensamento abissal: das linhas globais a uma ecologia de saberes. Revista crítica de ciências sociais, (78), 3-46.

Schwandt, T. A. (2006). Três posturas epistemológicas para a investigação qualitativa: interpretativismo, hermenêutica e construcionismo social. $O$ planejamento da pesquisa qualitativa: teorias e abordagens, 2, 193-217.

Torres, L. L., \& Palhares, J. A. (2009). Estilos de liderança e escola democrática. Revista Lusófona de Educação, (14), 77-99. 